\title{
Trust in the Doctor-Patient Relationship in Chinese Public Hospitals: Evidence for Hope
}

\author{
Yangyang Han', Reidar K Lie ${ }^{2}$, Zhenlin Li ${ }^{3}$ Rui Guo ${ }^{3}$ \\ 'Department of Outpatient, Beijing Hospital of Traditional Chinese Medicine, Capital Medical University, Beijing, People's Republic of China; \\ ${ }^{2}$ Department of Philosophy, University of Bergen, Bergen, Norway; ${ }^{3}$ School of Public Health, Capital Medical University, Beijing, People's Republic of \\ China
}

Correspondence: Rui Guo, School of Public Health, Capital Medical University, No. 10 Xitoutiao, Youanmenwai, Fengtai District, Beijing, 100069, People's Republic of China, Tel +86-10-839II573, Email guorui@ccmu.edu.cn

\begin{abstract}
Purpose: Trust is an essential component in a successful health care relationship. Doctor-patient trust involves the subjects of both sides, including the direction of patients' trust in physicians (patients' perception) and physicians' trust in patients (physicians' perception). This study aims to assess the status quo and explore suggestions for improving trust between doctors and patients.

Patients and Methods: In May 2018, we collected data from six representative hospitals in Beijing, China, including 610 questionnaires (310 physicians and 300 patients). Participants were Chinese-speaking, age 14 and older, who expressed their opinions clearly. Kruskal-Wallis $H$-test and Wilcoxon rank sum test were used to analyze the difference in the trust scores of the responses.

Results: Based on the doctor and patient characteristics, the data show that inpatients are trusted more than outpatients, and patients who often visit the clinic are more doubtful of doctors. The family trust is the highest, and social trust is the lowest. In general, the degree of trust between doctors and patients is good, but the score of physicians (Mean=3.87; $\mathrm{SD}=0.79$ ) is lower than that of patients (Mean=4.05; $\mathrm{SD}=0.76$ ). Physicians' evaluation of the degree of trust tends to be more negative than patients'.

Conclusion: In spite of recent negative press reports, there remains a high degree of trust between patients and doctors in Beijing. Despite this, one should not be complacent. We need to explore the root cause of the trust between doctors and patients from a deeper perspective to promote better medical services to meet the health needs of patients.
\end{abstract}

Keywords: China, doctor-patient relationship, trust, public hospitals

\section{Introduction}

Since 1978 China has experienced a period with several major health care system reforms. ${ }^{1,2}$ This has had a profound effect on the doctor-patient relationship in China. ${ }^{3}$ Public hospitals are the backbone of the Medical institutions in China, but they face the pressure of insufficient funds and demands of self-reliance. ${ }^{4}$ Although medical treatment has improved to ensure a more comprehensive medical service level, the health demand and supply gap still exists. ${ }^{5}$ High drug prices, difficult consultations, and irrational drug usage are obstacles for people seeking consultations from a doctor in recent years. ${ }^{6}$ People's demand for medical services has increased significantly. The imbalance between supply and demand because of existing high drug costs reports, and excessive medical treatments has brought pressure on the medical system. ${ }^{7}$ It wastes limited medical resources and causes tensions between doctors and patients and affects the people's trust in the whole medical system. ${ }^{8}$

For nearly ten years, the incidence of medical disputes in China has been rising in a straight line. ${ }^{9}$ The intensification of doctor-patient conflicts has seriously affected the normal order of diagnosis and treatment in hospitals. ${ }^{10}$ This has led to introducing a new word among medical professionals, called "medical harassers" (Yi nao). ${ }^{7}$ It is the conflicts between patients and doctors and the people in charge of organizing the trouble in order to obtain huge profits. In the doctorpatient conflicts, the patients obviously show indignation and hatred; Patients often suspect the actions of doctors and their motives and intentions. This vague uncertainty greatly weakens doctor-patient trust and leads to confrontation between doctors and patients. ${ }^{9}$ 
Mass media sometimes has not played a positive role in harmonizing the relationship. ${ }^{11}$ And the distorted coverage of such doctors in the Chinese media has exacerbated tensions between doctors and patients. ${ }^{12}$ The report overemphasized the tension between doctors and patients and overplayed the faults between doctors and patients, which increased the hostility of patients towards their doctors. ${ }^{13}$ Doctors often take a neutral attitude, frequently change treatment plans, refer patients, and consult with many experts. However, some media report such phenomena in a biased manner, and hospitals pay compensation for economic losses to achieve the purpose of silence, adding some mental pressure to medical staff. ${ }^{14}$ Under the conflicts between doctors and patients, doctors show obvious frustration and anger, resulting in the sense of a rejection of the profession. ${ }^{15}$ But in spite of this, everyone is aware that a doctor, to better understand the emotions and perspectives of the patient by trusting his patients, will give better treatment without fear of dispute. ${ }^{16-18}$

Although there are many anecdotal reports, there have not been many systematic studies in China about the trust between physicians and the public. And most previous studies have focused on patients' trust in their doctors, not vice versa. ${ }^{19}$ Also, there has been a tendency to study patients' trust in isolation from general trust towards other individuals. Therefore, the study aims to assess the patients' trust in doctors and compare that with the doctors' views, as well as place the trust in the doctor-patient relationship in a larger perspective of societal trust.

\section{Materials and Methods}

\section{Study Design}

The survey of doctor-patient trust in China included two questionnaires, one for doctors and one for patients. Only data from doctors and patients who responded were collected. In this study, we create an instrument to measure doctor-patient trust. We also collected and analyzed survey results according to the different parts of the questionnaires.

\section{Participants}

This study collaborated with six tertiary public hospitals to collect the respondents in May 2018 in Beijing, China. The hospitals serve both local and non-local population groups. Five were in the Dongcheng, Xicheng, and Chaoyang District, and a hospital was in the sub-center of a future city and included both Traditional Chinese and Western Medicine. The sample size was designed with a ratio of doctors to patients as $1: 1$. The actual sample size was 310 doctors, 300 patients (including outpatient and inpatient patients), and 610 respondents in total (the valid rate of 91.3\%) (Table 1). Inclusion and exclusion criteria: (1) Chinese-speaking, (2) age 14 and older who expressed their opinions clearly, and (3) volunteer for questionnaires.

\section{Instrument}

The research tool of the study was drafted based on the Interpersonal Trust Scale (ITS), "cha-xu pattern" and the Wake Forest Physician Trust Scale (WFPTS). ITS is used to measure the subject views on various situations of interpersonal trust, involving different social roles (including parents, politicians, and news media) in the general population. Most relate directly to social roles' trust, but some are also to the social level of optimism for the future. "20 "Cha-xu pattern" (difference pattern) is an important local concept to understand the Chinese social interpersonal pattern, in which the "difference" focuses on the "difference" equal structure of the individual social network, while the "pattern" emphasizes the "level order" of individual behavior or attitude. ${ }^{23}$ WFPTS is the instrument for the systematic assessment of patient trust according to five dimensions: honesty, competence, confidentiality, fidelity, and global trust. ${ }^{21,22}$

There are three parts of the questionnaire in the Chinese language (blank questionnaire forms, in Chinese and translated into English, are provided in Supplementary Files 1 and 2, respectively). The first section is about basic information, including gender, age, education, and other characteristics. The second part is about trust and it was conducted to understand the level of doctor-patient trust in hospitals from three trust dimensions: social trust, family trust, and doctor-patient trust. There were nine questions on family trust (9-45 points), with doctors scoring the lowest 11 points and the highest 45 points. The social trust had seven questions on a scale of 7-35 points. The doctor-patient trust level, there were thirteen questions for doctors (13-65 points) and 15 questions for patients (15-75 points). Furthermore, doctor-patient trust involves both sides' subjects, and doctors-patient trust directed of patients' trust in doctors and 
doctors' opinion of patients' trust. Each of the three dimensions has a different item problem to measure, each of which is summed up by the item score. They are in a typical 5-point Likert scale: Strongly disagree $=1$, Disagree $=2$, Neutral $=3$, Agree $=4$, Strongly agree $=5$. As shown in Figure 1, we divide the interpersonal distance into social trust and family trust according to the pattern of difference. ${ }^{24}$ The final part is the doctor-patient trust by multiple-choice questions, "What do you think about the doctor-patient trust in Beijing public hospitals."

\section{Analysis}

We used Epidata 3.0 to establish a database, double-recording the questionnaire data and selecting $30 \%$ of it randomly to ensure the quality of the survey. The descriptive and statistical method was used to analyze in SPSS 25.0.

Binary logistic regression was performed to investigate the association of demographic factors with trust degree. The trust degree group is divided by the answer to the questionnaire final part by multiple-choice questions. The low degree group is Strongly distrust and Distrust, and the high degree group is others.

The second part of the questionnaire is about social trust, family trust, and doctor-patient trust. We added the individual scores to obtain a total trust score for each dimension and computed an average.

Trust $=\frac{\sum_{i, j} n_{i j} j}{\sum_{i, j} 5 n_{i j}} \times 100 \% \mathrm{i}=\mathrm{p}, \mathrm{p}+1, \ldots, \mathrm{q} ; \mathrm{j}=1,2,3,4,5$

Last, Wilcoxon Signed-Rank test was used to analyze the difference in the trust scores of the responses.

\section{Quality Control}

We unified training of investigators and evaluation criteria, and before the interview, we unified training interview personnel, unified precise evaluation scale. On the premise of not hindering the participants' work and medical treatment, the interviewee should fully communicate with the interviewer to obtain information that can reflect the real situation; carry out the work in a standardized manner, and conduct data sorting and entry at the end of the interview and questionnaire survey.

Investigators completed the entry and verification work within three days and submitted the electronic version of the paper version to conduct telephone return visits for the empty items and missing items in the questionnaire to ensure the data quality.

\section{Results}

The characteristics of respondents are shown in Table 1.300 patients and 310 doctors made up the sample in the present analysis (Table 1). The mean age in the patient group was about 47 years (range 14-87 years), 90. 5\% of all patients ranged between 25 and 54 years; $52.3 \%$ were females. For $50.0 \%$ of the patients, the level of education was higher than Junior college, $41.3 \%$ of the patients were middle and high School, and $8.7 \%$ were Primary school and below. 50.3\% of the patients were outpatients. Furthermore, $66.7 \%$ of patients had a household registration in Beijing, and the Urban Employee Basic Health Insurance (UEBHIS) and Urban citizen Basic Health Insurance (UCBHIS) covered 89.3\%. For the doctor group, the mean age was about 42 years (range $24-70$ years), $90.5 \%$ of all doctors ranged between 25 and 54 years, $62.3 \%$ were female, and $99.4 \%$ of the level of education was higher than Junior college. The vast majority of them had intermediate or higher titles.

Table 1 shows comparisons of related factors between the low and high degree of trust group, respectively, and univariate analysis using the Chi-square test was performed. In the present study, the variables that showed inpatients and outpatients, and between patients with different numbers of outpatient visits were statistically significantly different. Patients' variables, including gender, age, household registration, education, health insurance, and all doctors' variables, did not show statistical significance. Therefore, to identify predictive factors, the in/outpatient status and the number of outpatients' visits last year are used as logistic regression variables. As shown in Table 2, the data shows that inpatients are trusted more than outpatients, and patients who often visit the clinic are more distrustful of doctors. The patients' source factor was positively associated with trust $(\mathrm{OR}=4.69,95 \% \mathrm{CI} 1.52-14.41, P=0.01)$. The number of visits factor was negatively associated with trust degree $(\mathrm{OR}=0.65,95 \% \mathrm{CI} 0.44-0.95, P=0.01)$.

The results of the different levels of doctor-patient trust are provided in Table 3. Doctors scored the lowest 11 points and the highest 45 points, with patients scoring the lowest 12 points and the highest 45 points on family trust. 
Table I General Characteristics of Doctor and Patient

\begin{tabular}{|c|c|c|c|c|c|c|}
\hline \multirow[t]{2}{*}{ Characteristic } & \multirow[t]{2}{*}{$\mathbf{N}$} & \multirow[t]{2}{*}{$\%$} & \multicolumn{2}{|c|}{ Group of Trust } & \multirow[t]{2}{*}{$\chi^{2}$} & \multirow[t]{2}{*}{$P$-value } \\
\hline & & & Low Degree & High Degree & & \\
\hline \multicolumn{7}{|l|}{ Gender } \\
\hline Male & 143 & 47. 7 & 11 & 132 & 0.20 & 0.65 \\
\hline Female & 157 & 52. 3 & 10 & 147 & & \\
\hline \multicolumn{7}{|l|}{ Age [years] } \\
\hline$\leq 24$ & 22 & 7. 3 & 2 & 20 & 0.20 & 0.65 \\
\hline $25-34$ & 60 & 20.0 & 1 & 59 & & \\
\hline $35-44$ & 51 & 17. 0 & 7 & 44 & & \\
\hline $45-54$ & 50 & 16. 7 & 2 & 48 & & \\
\hline$\geq 55$ & 117 & 39. 0 & 9 & 108 & & \\
\hline \multicolumn{7}{|l|}{ Source } \\
\hline Outpatient & $|5|$ & 50.3 & 17 & 134 & 8.47 & $<0.05^{*}$ \\
\hline Inpatient & 149 & 49. 7 & 4 & 145 & & \\
\hline \multicolumn{7}{|l|}{ Household registration } \\
\hline Beijing & 200 & 66. 7 & 15 & 185 & 0.23 & 0.63 \\
\hline Other places & 100 & 33. 3 & 6 & 94 & & \\
\hline \multicolumn{7}{|l|}{ Education } \\
\hline Primary school and below & 26 & 8. 7 & 0 & 26 & 0.05 & 0.82 \\
\hline Middle school & 63 & 21.0 & 5 & 58 & & \\
\hline High school & 61 & 20.3 & 8 & 53 & & \\
\hline Junior college & 62 & 20.7 & 3 & 59 & & \\
\hline Undergraduate and above & 88 & 29. 3 & 5 & 83 & & \\
\hline \multicolumn{7}{|l|}{ Number of visits } \\
\hline 0 & 55 & 18. 4 & 0 & 55 & 4.78 & $0.03 *$ \\
\hline $\mathrm{I}-2$ & 117 & 39. 1 & 9 & 108 & & \\
\hline $3-6$ & 73 & 24. 4 & 6 & 67 & & \\
\hline $7-11$ & 30 & 10.0 & 2 & 28 & & \\
\hline$>12$ & 24 & 8. 0 & 4 & 20 & & \\
\hline \multicolumn{7}{|l|}{ Health insurance } \\
\hline UEBHIS & 162 & 54. 0 & 14 & 148 & 2.40 & 0.66 \\
\hline UCBHIS & 106 & 35. 3 & 6 & 100 & & \\
\hline $\mathrm{CHI}$ & 4 & I. 3 & 0 & 4 & & \\
\hline $\mathrm{FHI}$ & 15 & 5. 0 & 0 & 15 & & \\
\hline without any health insurance & 13 & 4. 3 & I & 12 & & \\
\hline \multicolumn{7}{|l|}{ Doctors age } \\
\hline$\leq 24$ & 2 & 0.7 & 0 & 2 & 2. 60 & 0.77 \\
\hline $25-34$ & 75 & 24. 5 & 19 & 56 & & \\
\hline $35-44$ & 101 & 33. 0 & 22 & 79 & & \\
\hline $45-54$ & 101 & 33. 0 & 30 & 71 & & \\
\hline $55-59$ & 22 & 7. 2 & 7 & 15 & & \\
\hline$\geq 60$ & 5 & 1.6 & 1 & 4 & & \\
\hline \multicolumn{7}{|l|}{ Doctors gender } \\
\hline Male & 117 & 37. 7 & 32 & 85 & 0.35 & 0.56 \\
\hline Female & 193 & 62. 3 & 47 & 146 & & \\
\hline
\end{tabular}

(Continued) 
Table I (Continued).

\begin{tabular}{|c|c|c|c|c|c|c|}
\hline \multirow[t]{2}{*}{ Characteristic } & \multirow[t]{2}{*}{$\mathbf{N}$} & \multirow[t]{2}{*}{$\%$} & \multicolumn{2}{|c|}{ Group of Trust } & \multirow[t]{2}{*}{$\chi^{2}$} & \multirow[t]{2}{*}{$P$-value } \\
\hline & & & Low Degree & High Degree & & \\
\hline \multicolumn{7}{|l|}{ Doctors education } \\
\hline Doctor degree & 80 & 25. 8 & 19 & 61 & I. 48 & 0.85 \\
\hline Master degree & 80 & 25. 8 & 24 & 56 & & \\
\hline Undergraduate & 112 & 36. 1 & 28 & 84 & & \\
\hline Junior College & 36 & 11.6 & 8 & 28 & & \\
\hline Senior High School/Technical Secondary School & 2 & 0.6 & 0 & 2 & & \\
\hline \multicolumn{7}{|l|}{ Doctors title } \\
\hline Senior Manager & 61 & 19. 7 & 15 & 46 & 4. 34 & 0.36 \\
\hline Deputy senior & 69 & 22. 3 & 24 & 45 & & \\
\hline Intermediate & 99 & 31.9 & 22 & 77 & & \\
\hline Primary & 74 & 23. 9 & 16 & 58 & & \\
\hline No title & 7 & 2. 3 & 2 & 5 & & \\
\hline
\end{tabular}

Notes: *There was a significant difference at $P<0.05$. Low degree groups include strongly disagree, disagree, and neutral.

Abbreviations: uebhis, urban employee basic health insurance; UCBHIS, urban citizen basic health insurance; $\mathrm{CHI}$, commercial health insurance; FHI, free health insurance.

And, doctors scored the lowest on 7 and the highest on 34, and patients scored the lowest 14 points and the highest 32 points on social trust. Also, the doctor-patient trust level, their lowest scores were 32 and 33, and their highest scores were full. This 3D plot shows every participant's social trust, family trust, and doctor-patient trust score (Figure 2). The plot shows that the three variables were not correlated, but trust scores were mostly above neutral.

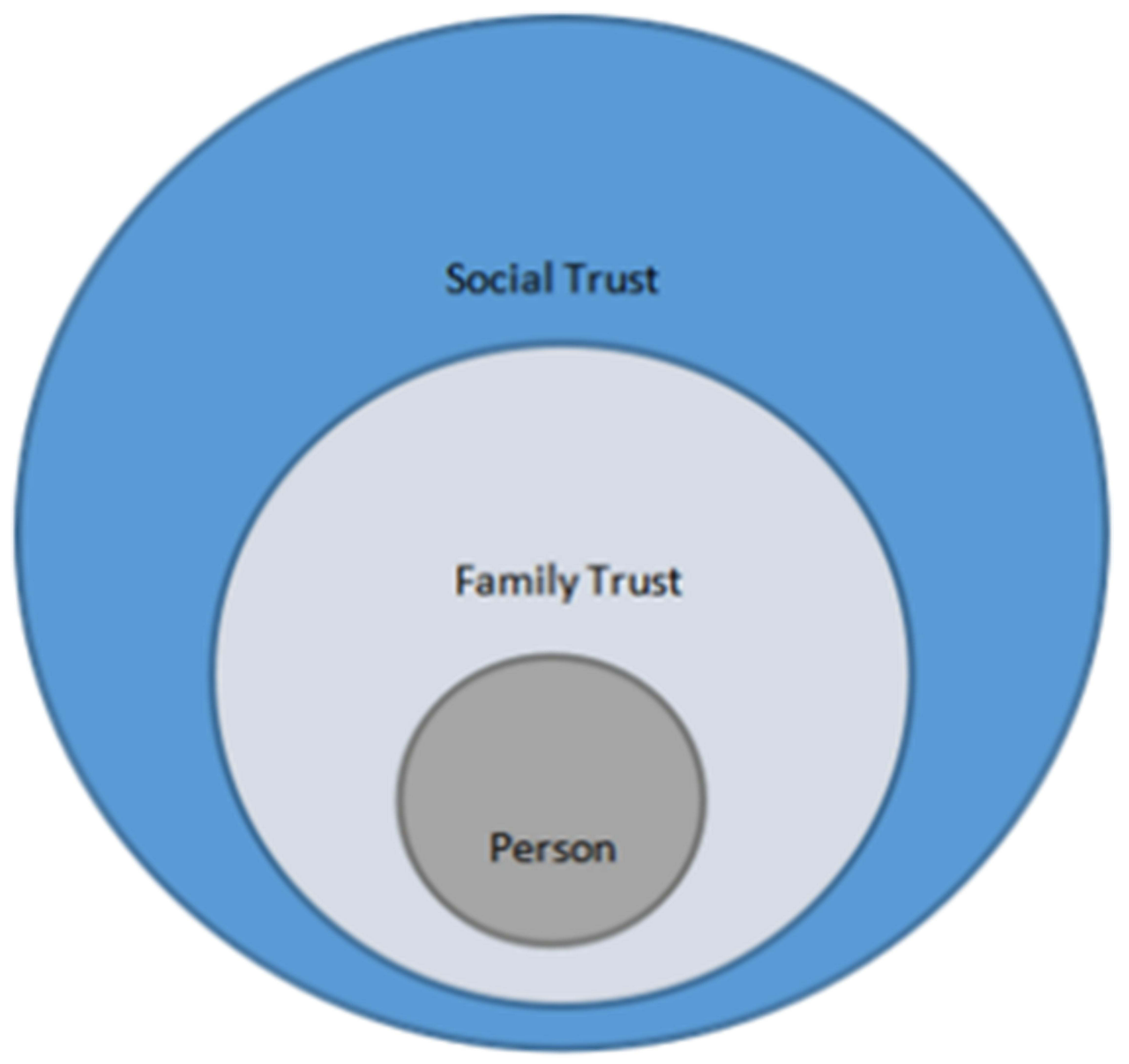

Figure I The relationship between social trust and family trust. 
Table 2 Multivariate Regression Analysis Results

\begin{tabular}{|l|l|l|l|l|l|}
\hline \multirow{2}{*}{} & \multicolumn{2}{|c|}{ B } & \multicolumn{2}{c|}{ P-value } & \multicolumn{2}{c|}{ OR } & \multicolumn{2}{c|}{$95 \%$ CI } \\
\cline { 3 - 6 } & & & & Lower Bound & Upper Bound \\
\hline Source & 1.54 & 0.01 & 4.69 & 1.52 & 14.41 \\
Number of visits & -0.43 & 0.03 & 0.65 & 0.44 & 0.95 \\
Constant & 1.70 & 0.06 & 5.45 & & \\
\hline
\end{tabular}

Internal consistencies were high for two scales (Cronbach's $\alpha>0.80$ ), and the coefficient of the Social Trust Scale is low only at the edge of the acceptable range. The Kaiser-Meyer-Olkin (KMO) measure of sampling adequacy of 0.938 and 0.920 , and Bartlett's test of sphericity $(\mathrm{P}<0.001)$ indicated that the validity of the scale indicated positive results. The average score of social trust was more than 21 (all items were selected as "Neutral"); the average score of family trust was more than 27; and the average score of doctor-patient trust was more than 39 , all items were higher than the neutral level in Table 3.

In order to compare the overall situation of each scale intuitively and calculate the "trust degree" to reflect, the order of trust degree from high to low is the family trust, doctor-patient trust, and social trust. The value of trust and the average score of the scale are fixed multiples. As shown in Figure 3, among the three types of scales, family trust is the highest, and social trust is the lowest, and they have statistical significance.

We finally asked a single question about the respondents' perception of trust in the doctor-patient relationship in Beijing hospitals. The results are provided in Table 4. 81.6\% of patients chose "trust and strongly trust", $15.4 \%$ chose "neutral", and only 3.0\% chose "distrust and strongly distrust", the average value after the assignment was 4.05 $(\mathrm{SD}=0.76$ ), indicating that the overall level tended to "trust". $74.5 \%$ of the doctors chose "trust and strongly trust", $20.6 \%$ of people chose "neutral", $4.8 \%$ distrust and strongly distrust, the average value after the assignment was 3.87 ( $\mathrm{SD}=0.79$ ), and the knowledge of trust tended to be "trust". Rank sum test $\mathrm{Z}=-10.471, P<0.001$, showed that the difference between doctors and patients was statistically significant. Generally speaking, the degree of trust between doctors and patients is better, but the score of doctors is lower than that of patients. Doctors' evaluation of the degree of trust between doctors and patients tends to be more negative.

\section{Discussion}

The surprising finding is that there is a high degree (Mean=3.87, $\mathrm{SD}=0.79$; Mean $=4.05, \mathrm{SD}=0.76$ ) of trust between patients and doctors in China, in spite of the picture portrayed in the media about a breakdown of trust between patients and doctors. Patients trust doctors somewhat less than their own family members but higher than the average for other groups in society, same as Czech situation. ${ }^{25}$ Both the high level of trust in general and the fact that trust in doctors is ranked lower than trust in family members but higher than trust in other social groups strengthen the confidence in the reported trust between doctors and patients.

There may be several explanations for this. First, it may be that the media has a tendency to focus on a few extreme cases as representative of the general doctor-patient relationship in China and that these few cases are simply not representative. ${ }^{26,27}$ Second, it may be that our sample from Beijing is not representative of the general situation in China. Third, it may be that our survey instrument does not adequately capture the social reality in China. Fourth, and this is perhaps the most likely reason, rising expectations for the health care system's performance among the Chinese population may lead to more vocal criticism, even though there is still a general satisfaction with the quality of the service provided. ${ }^{28}$

Our data also show a remarkable similarity in the answers of the patients and the doctors regarding their views about trust in others. Patients and doctors also have very similar views regarding specific items in evaluating patients' trust in doctors. Only when we ask directly about their view of the level of trust between doctors and patients do we find that doctors have a more negative view than patients of how much patients trust doctors in Beijing. In spite of this, both groups generally have a largely positive view of the level of trust between patients and doctors. 
Table 3 Comparison of Trust Scores

\begin{tabular}{|c|c|c|c|c|c|c|c|c|c|c|c|c|c|c|}
\hline \multirow[t]{2}{*}{ Dimension } & \multicolumn{7}{|c|}{ Doctor } & \multicolumn{7}{|c|}{ Patient } \\
\hline & Item & Cronbach's Alpha & KMO-Bartlett & Min & Max & $\bar{x} \pm s$ & Trust & Item & Cronbach's Alpha & KMO-Bartlett & Min & Max & $\bar{x} \pm s$ & Trust \\
\hline Family trust & 9 & 0.91 & $0.938^{*}$ & 11 & 45 & $\begin{array}{l}41.3 \\
\pm 4.9\end{array}$ & $91.8 \%$ & 9 & 0.86 & $0.920^{*}$ & 12 & 45 & $\begin{array}{r}41.9 \\
\pm 4.4\end{array}$ & 93. $2 \%$ \\
\hline Social trust & 7 & 0.66 & & 7 & 34 & $\begin{array}{l}24.6 \\
\pm 3.6\end{array}$ & $70.3 \%$ & 7 & 0.65 & & 14 & 32 & $\begin{array}{l}24.6 \\
\pm 3.5\end{array}$ & 70. $5 \%$ \\
\hline Doctor-patient trust & 13 & 0.92 & & 32 & 65 & $\begin{array}{l}56.5 \\
\pm 7.1\end{array}$ & $86.9 \%$ & 15 & 0.90 & & 33 & 75 & $\begin{array}{r}64.6 \\
\pm 8.6\end{array}$ & 86. $2 \%$ \\
\hline
\end{tabular}

Notes: *There was a significant difference at $P<0.05$. 

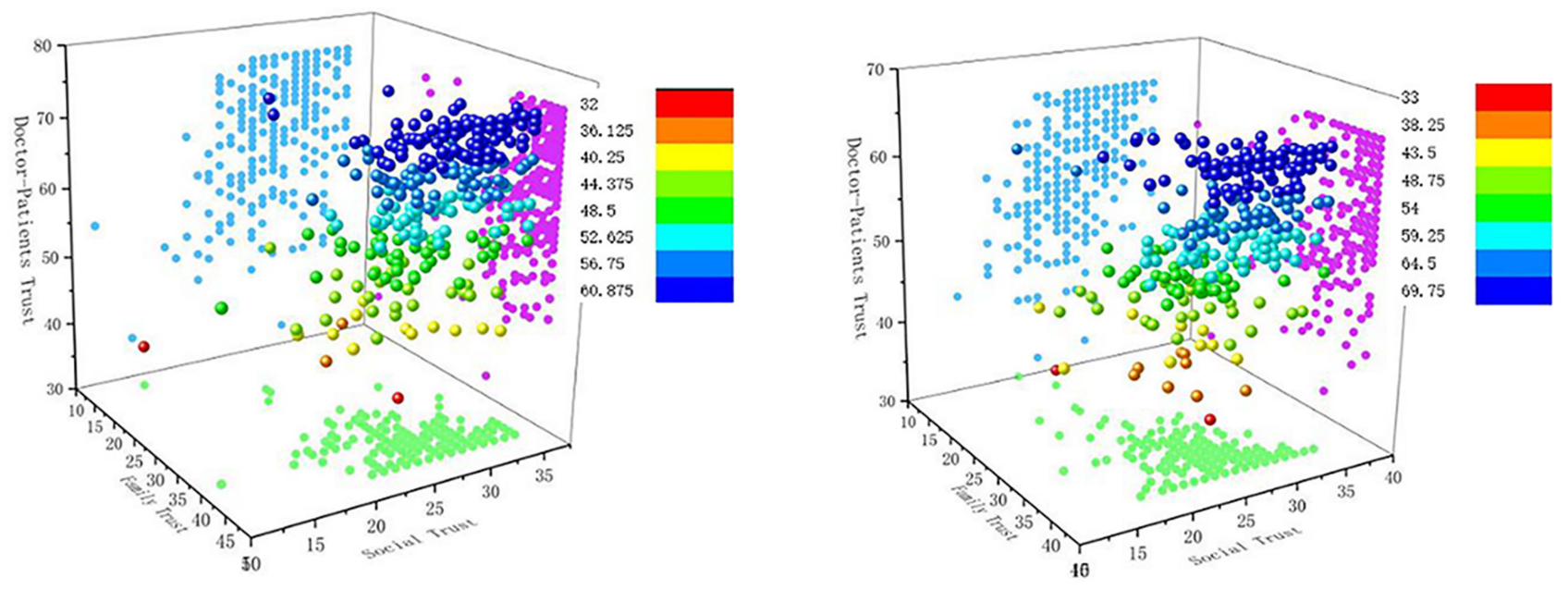

A

B

Figure 2 Patients (A) and doctors (B) social trust, family trust, and doctor-patient trust score 3-D scatter plot.

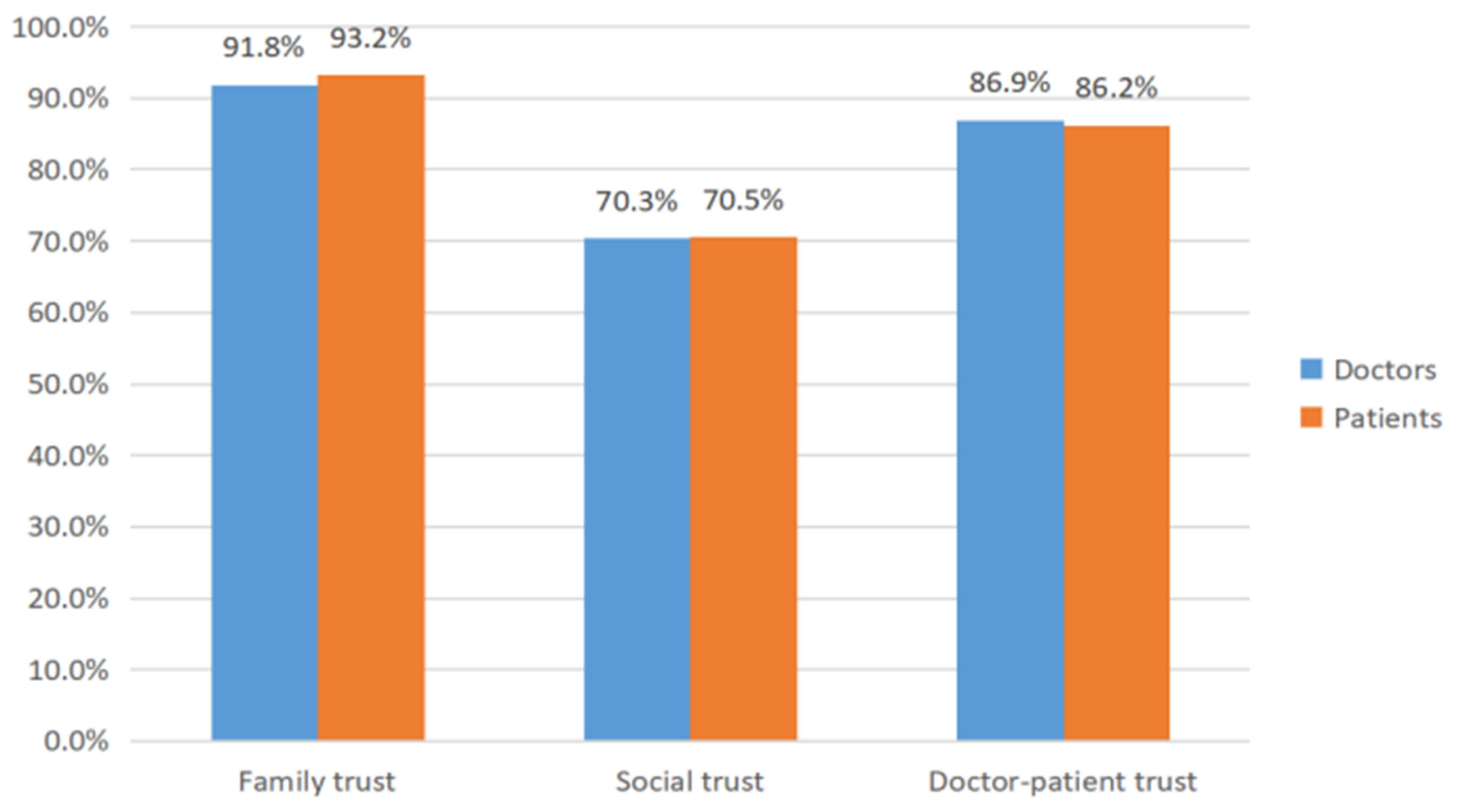

Figure 3 Three types of trust indices between doctors and patients.

Even though our results indicate that the situation is better than that portrayed in typical media reports, there is no reason for complacency. ${ }^{29,30}$ If the reported low level of trust results from rising expectations, the high trust level reported in our study might be fragile. This study, therefore, suggests improving the medical information asymmetry phenomenon. First of all, increasing patient-centered service awareness further, while maintaining strict ethics to account for the patient-doctor power differential has been shown to increase trust and strengthen the doctor-patient relationship. $^{31,32}$ And then, both doctors and patients should put themselves in others' shoes, because many medical 
Table 4 Doctor-Patient Trust Grade

\begin{tabular}{|l|c|c|c|c|c|c|}
\hline \multirow{2}{*}{ Trust Situation } & \multicolumn{3}{|c|}{ Doctor } & \multicolumn{3}{c|}{ Patient } \\
\cline { 2 - 7 } & N & $\%$ & Mean & N & $\%$ & Mean \\
\hline Strongly distrust & 3 & 1.0 & 3.87 & 2 & 0.7 & 4.05 \\
Distrust & 12 & 3.9 & & 7 & 2.3 & 15.4 \\
Neutral & 64 & 20.6 & & 163 & 54.5 & 27.1 \\
Trust & 173 & 55.8 & & 81 & 100.0 & \\
Strongly Trust & 58 & 18.7 & & 299 & \\
Total & 310 & 100.0 & & & & \\
\hline
\end{tabular}

Notes: Strongly distrust $=\mathrm{I}$, Distrust $=2$, Neutral $=3$, Trust $=4$, Strongly trust $=5$.

schools, residencies, and health systems have implemented programs to increase physician empathy and communication skills; these programs have been shown to increase mutual trust and decrease medical disputes. ${ }^{33}$ Last but not least, the media should correctly and objectively report doctor-patient incidents and should not deliberately favor and intensify the information disadvantage of patients in order to cater to the psychology that the weak should be protected.

In general, to build an ideal doctor-patient relationship and re-establish mutual trust between doctors and patients not only depend on the credible assurance provided by the hospital system level and the individual level of medical staff but also need to establish mutually reinforcing expectations through conventions, culture, and keeping promises in the macro-environment, industry environment and organizational environment. These expectations will lead to Inter-member cooperation and trust-building.

This study has several limitations that should be borne in mind when interpreting the results. Firstly, the study only enrolled patients who are suffering from more severe diseases. The severity of the disease may affect a patients' trust in a doctor. And there are no low-level medical institutions in our survey. Doctors in low-level hospitals may have limited technical skills and insufficient service to treat diseases timely and accurately, thus affecting patients' trust. ${ }^{34}$ Also, in the study, it was found that the source of patients and the number of outpatient visits would affect the trust of patients, and the reasons would be explored in future studies. Moreover, we should also continue to explore the factors that influence doctors' lower trust than patients. Also, cross-sectional survey data provide only a snapshot of dynamic, temporally distributed, nonlinear phenomena. ${ }^{35}$ Finally, we realized that it was necessary to use our questionnaire to investigate on doctor-patient trust internationally, such as in the United States and Europe, to further provide a description and comparison of the current level of doctor-patient trust, so as to conduct more meaningful research.

\section{Conclusion}

Trust is critical to fostering a positive doctor-patient relationship. According to empirical evidence from six public hospitals in Beijing, in spite of recent negative press reports, there remains a high degree of trust between patients and doctors. Despite this, one should not be complacent. We need to explore the root cause of the trust between doctors and patients from a deeper perspective to promote better medical services to meet the health needs of patients.

\section{Abbreviations}

ITS, interpersonal trust scale; WFPTS, wake forest physician trust scale; UEBHIS, urban employee basic health insurance; UCBHIS, urban citizen basic health insurance; CHI, commercial health insurance; FHI, free health insurance; KMO, Kaiser-Meyer-Olkin.

\section{Data Sharing Statement}

The datasets used and/or analyzed during the current study are available from the corresponding author on reasonable request. 


\section{Ethics Approval and Consent to Participate}

All procedures of this study performed in studies involving human participants were in accordance with the ethical standards of the institutional and/or national research committee and with the 1964 Helsinki Declaration and its later amendments or comparable ethical standards. The study was approved by the Medical Ethics Committee of Capital Medical University (No. IRB00005735) in writing, and all participants gave informed consent. And we obtained written informed consent from the participants and the parent or guardian for participants under 18 years old.

\section{Acknowledgments}

The authors wish to thank Yi Dong for his helpful comments during the early stages of this research and for connecting with the six hospitals to conduct the survey, and Yuxuan Wang and Chenxin Liu for their help in the data processing.

\section{Author Contributions}

All authors made a significant contribution to the work reported, whether that is in the conception, study design, execution, acquisition of data, analysis and interpretation, or in all these areas; took part in drafting, revising or critically reviewing the article; gave final approval of the version to be published; have agreed on the journal to which the article has been submitted; and agree to be accountable for all aspects of the work.

\section{Funding}

This work was supported by the Research Center for Capital Health Management and Policy (No. 2017JD03), the National Natural Science Foundation of China (No. 71704118).

\section{Disclosure}

The authors report no conflicts of interest in this work.

\section{References}

1. Li L, Fu HQ. China's health care system reform: progress and prospects. Int J Health Plann Manage. 2017;32:240-253.

2. Chen Z. Launch of the health-care reform plan in China. The Lancet. 2009;373:1322-1324.

3. Meng QY. Developing and implementing equity-promoting health care policies in China. Chinese Health Econ. 2007;01:9-14.

4. Lu H, Li JB, Xu DX, Ren JS. Problems in introduction of funds to lessen burden in national hospitals. Hosp Admin J Pla. 2005;12:68-70.

5. Meng QY. Medical reform should solve the imbalance between supply and demand of medical services. Health Econ Res. 2014;10:65-67.

6. Kou ZL. Why medical care is expensive and hard to be obtained in China? J World Econ. 2010;1:49-68.

7. He AJ. The doctor-patient relationship, defensive medicine and over prescription in Chinese public hospitals: evidence from a cross-sectional survey in Shenzhen city. Soc Sci Med. 2014;123:64-71.

8. Zeng YX. How to control over medical treatment. QiuShi. 2014;5:51-52.

9. Calnan M, Hall MA. Researching medical trust in the United States. J Health Organ Manag. 2006;20(5):456-467.

10. Feng JM, Li YM, Han CG, Xu L, Duan LS. Retrospective analysis of 418 medical dispute literature. Chin Hosp Manage. 2013;33(9):77-79.

11. Sun J, Liu SY, Liu QN, et al. Impact of adverse media reporting on public perceptions of the doctor-patient relationship in China: an analysis with propensity score matching method. BMJ Open. 2018;8:e22455.

12. Deng HM. Review and ethical reconstruction of doctor-patient relationship in early 21st century TV series. Shandong Social Sci. 2012;11:115-119.

13. Jacobs AK. Rebuilding an enduring trust in medicine: a global mandate: presidential address American heart association scientific sessions 2004. Circulation. 2005;111(25):3494-3498.

14. Sun JJ, Zhang LP, Sun RC, et al. Exploring the influence of resiliency on physician trust in patients: an empirical study of Chinese incidents. PLoS One. 2018;13(12):e0207394.

15. Cao J. Patients' perception of the physician-doctor relationship. Chinese Med Ethics. 2008;21:84-86.

16. Yu LL, Yan YH. The impact of trust, interaction, and empathy in doctor-patient relationship on patient satisfaction. J Nurs Health Stud. 2017;2:2-8.

17. Hojat M, Gonnella JS, Nasca TJ, Mangione S, Vergare M, Magee M. Physician empathy: definition, components, measurement, and relationship to gender and specialty. Am J Psychiatry. 2002;159(9):1563-1569.

18. Flickingera TE, Sahab S, Roterd D, et al. Clinician empathy is associated with differences in patient-clinician communication behaviors and higher medication self-efficacy in HIV care. Patient Educ Couns. 2016;99(2):220-226.

19. Wilk AS, Platt JE. Measuring doctors' trust: a scoping review with implications for public policy. Soc Sci Med. 2016;165:75-81.

20. Rotter JB. A new scale for measurement of interpersonal trust. J Pers. 1968;35(4):651-665.

21. Dugan E, Trachtenberg F, Hall MA. Development of abbreviated measures to assess patient trust in a physician, a health insurer, and the medical profession. BMC Health Serv Res. 2005;5(1):64.

22. Dong EH, Liang Y, Liu W, et al. Construction and validation of a preliminary Chinese version of the wake forest physician trust scale. Med Sci Monit. 2014;20(32):1142-1150.

23. Hu AN. How differential is the differential mode of association? An empirical measure. J Soc Sci. 2018;1:64-74. 
24. Fei XT. From the Soil: The Foundations of Chinese Society. Berkeley and Los Angeles, California: University of California Press; 1992.

25. Kisvetrova H, Školoudík D, Danielová L, et al. Czech version of the patient dignity inventory: translation and validation in incurable patients. J Pain Symptom Manage. 2018;55(2):444-450.

26. Lu Y. Kill the doctors. Available from: http://www.globaltimes.cn/content/827820.shtml. Accessed November 4, 2021.

27. Editorial. Protecting Chinese doctors. The Lancet. 2020;395:90.

28. Bai Y Bai Yansong's latest remarks have triggered a strong resonance in the medical community. Available from: https://www.sohu.com/a/ 356788632_100092991?scm=1002.580041.1040132.PC_ARTICLE_FOCUS. Accessed November 4, 2021.

29. Hefei Online. How bad is the doctor-patient relationship? Available from: https://www.sohu.com/a/81970283_119865. Accessed November 4, 2021.

30. Baijiahao. Beijing female doctor is cut wound, rescue invalid dead, how should contradiction of doctor and patient treat. Available from: https:// baijiahao.baidu.com/s?id=1653785117742802028\&wfr=spider\&for=pc. Accessed November 4, 2021.

31. Qu S. Thirty-nine guidelines govern physician ethics. Medical Frontier. 2014;15.

32. Schilke O, Reimann M, Cook KS. Power decreases trust in social exchange. Proc Natl Acad Sci U S A. 2015;112:12950-12955.

33. Liu HL, Liu HJ. Empathy: access to rebuilding confidence relationship between doctors and patients. Chinese Med Ethics. 2012;025(003):347-349.

34. Wu HL, Hao J, Yang J. Study on the patient trust assessment and influencing factors in different level medical institutions in Beijing. Chinese Hosp. 2018;22(02):26-29.

35. Hall MA, Zheng B, Dugan E. Measuring patients' trust in their primary care providers. Med Care Res Rev. 2002;59(3):293.

\section{Publish your work in this journal}

Patient Preference and Adherence is an international, peer-reviewed, open access journal that focusing on the growing importance of patient preference and adherence throughout the therapeutic continuum. Patient satisfaction, acceptability, quality of life, compliance, persistence and their role in developing new therapeutic modalities and compounds to optimize clinical outcomes for existing disease states are major areas of interest for the journal. This journal has been accepted for indexing on PubMed Central. The manuscript management system is completely online and includes a very quick and fair peer-review system, which is all easy to use. Visit http://www.dovepress.com/testimonials.php to read real quotes from published authors.

Submit your manuscript here: https://www.dovepress.com/patient-preference-and-adherence-journal 